\title{
CARACTERIZACION HIDROLOGICA DEL RIO ARGA (NAVARRA): EL AGUA COMO RECURSO Y COMO RIESGO
}

POR

A. BESCOS

Y

A. M. CAMARASA

\section{Introducción}

El agua constituye un elemento vital para el desarrollo de los ecosistemas naturales, así como de los enclaves humanos. Mucho más que la tierra, resulta determinante en el devenir histórico de las poblaciones de países mediterráneos. No es extraño, por ello, que, desde la antigüedad, las áreas cercanas a los ríos sean zonas preferentes para la instalación de núcleos urbanos y actividades productivas ligadas al consumo de agua. Las llanuras de inundación constituyen el sustrato idóneo para el desarrollo agrícula dada la fertilidad de los materiales detríticos que en ellas se acumulan. Asimismo, procuran un marco apetecible para las actividades industriales que, a menudo, priman factores de localización relacionados con la disponibilidad de agua, la infraestructura viaria propia de zonas llanas y la proximidad de núcleos urbanos.

A. Bescos y A. M. Camarasa. Departamento de Geografía. Universidad de Alcalá. 
Sin embargo, la relación hombre-medio entorno al agua no siempr resulta positiva. En un país como el nuestro, el tema del agua presenta dos facetas de signo contrario; por una parte, es un recurso deficitario y, por otra, constituye un importante riesgo potencial. Las llanuras de inundación, que tanto atraen a la población, son, como su propio nombre indica, los espacios naturalmente sometidos a anegamientos recurrentes (Roselló, 1989).

La creciente ocupación antrópica de los valles aluviales, con las modificaciones que ello implica en el funcionamiento de los sistemas fluviales afectados, está creando conflictos, cada vez más patentes entre el uso del recurso y la prevención del riesgo. Así, por una parte, el agua constituye un recurso económico, cuya disponibilidad puede condicionar el desarrollo de importantes actividades productivas. Por otra parte, la ocupación indiscriminada de las llanuras aluviales conlleva un considerable factor de riesgo para hombres y bienes.

Estos problemas, comunes a la mayor parte de las cuencas españolas, adquieren una dimensión considerable en el caso del río Arga. Afluente del Ebro, drena el $25 \%$ del territorio navarro y concreta, según el censo de 1991, un total de 328.436 habitantes (62\% de los habitantes navarros). Tanto la población como las actividades económicas vienen experimentando una importante expansión desde los años 60 , vinculada, sobre todo, al desarrollo industrial. Pamplona y su área metropolitana son las zonas que sufren los mayores cambios. También, es importante la difusión de la industria a través del corredor del Araquil, o su implantación en núcleos puntuales como Peralta (Ferrer y Calvo, 1988; Ferrer et al., 1991). Todo ello se traduce en un incremento considerable de las demandas hídricas para uso urbano e industrial, sobre todo en el Area Metropolitana de Pamplona y de Alsasua y, para regadío, en los municipios de la cuenca baja.

Esta expansión antrópica genera una gran presión sobre los llanos aluviales que se ven sometidos a la ocupación indiscriminada de terrazas bajas y lóbulos de meandros. Cada vez son más los barrios de Pamplona sometidos a riesgo de inundación, tanto de uso residencial (Rochapea, Chantrea) y agrícola (La Magdalena, Aranzadi), como industrial (polígono de Landaben). También en los municipios de la cuenca baja, entre Berbizana y Funes, de producción fundamentalmente agraria, el riesgo de inundación se ha incrementado en los últimos 20 años. Las obras hidráulicas, recientemente finalizadas en la cuenca del Arga (rec- 
tificación y canalización de meandros, 1996), no acaban de solucionar el problema, tal y como lo demuestran las inundaciones acaecidas, apenas un año después, en enero de 1997.

Todo ello conduce a la necesidad de planteamientos globales que aborden el estudio de las cuencas fluviales como un sistema hidrogeomorfológico (Gregory y Walling, 1973; López Bermúdez et al., 1988), en relación con el hombre que lo ocupa. En este contexto, el presente trabajo estudia el comportamiento del río Arga bajo una perspectiva integral que contempla el agua en sus facetas de recurso y riesgo. Se analizan los aspectos físicos que determinan el funcionamiento hidrológico de la cuenca, así como los factores humanos, de demanda hídrica y ocupación del llano, que operan sobre el sistema, tanto para extraer rendimientos en situaciones de caudales ordinarios, como para protegerse del riesgo en crecidas extraordinarias.

Entendemos que este tipo de estudio puede constituir un eficaz instrumento de planificación territorial y de gestión hídrica, al tiempo que un componente fundamental en los programas de previsión y protección contra avenidas ${ }^{1}$.

\section{La cuenca del río Arga}

La cuenca hidrográfica del río Arga constituye una importante subcuenca del río Ebro. Posee una superficie de $2.733 \mathrm{~km}^{2}$, de la cual el $96 \%\left(2.618 \mathrm{~km}^{2}\right.$ pertenece al territorio navarro y el $4 \%\left(115 \mathrm{~km}^{2}\right)$ restante, a la vecina provincia de Alava. Presenta forma alargada (de alineación N-S) y asimétrica, con mayor desarrollo de la margen derecha, por donde recibe los principales afluentes: ríos Ulzama, Araquil y Salado. Por la margen izquierda solo es destacable la aportación del río Elorz (figura 1).

Características de medio físico.-El rasgo característico del río Arga radica en la heterogeneidad de sus componentes físicos y humanos. Desde que, en los años 50, Casas Torres (1956) calificara este aspecto

\footnotetext{
${ }^{1}$ Este trabajo está en relación con la memoria de licenciatura que, bajo el título de Estudio integral de la Cuenca Hidrográfica del río Arga: el agua como recurso y como riesgo, fue defendida en la Universidad de Alcalá de Henares y dirigida por los doctores Sancho Comins y Camarasa Belmonte.
} 


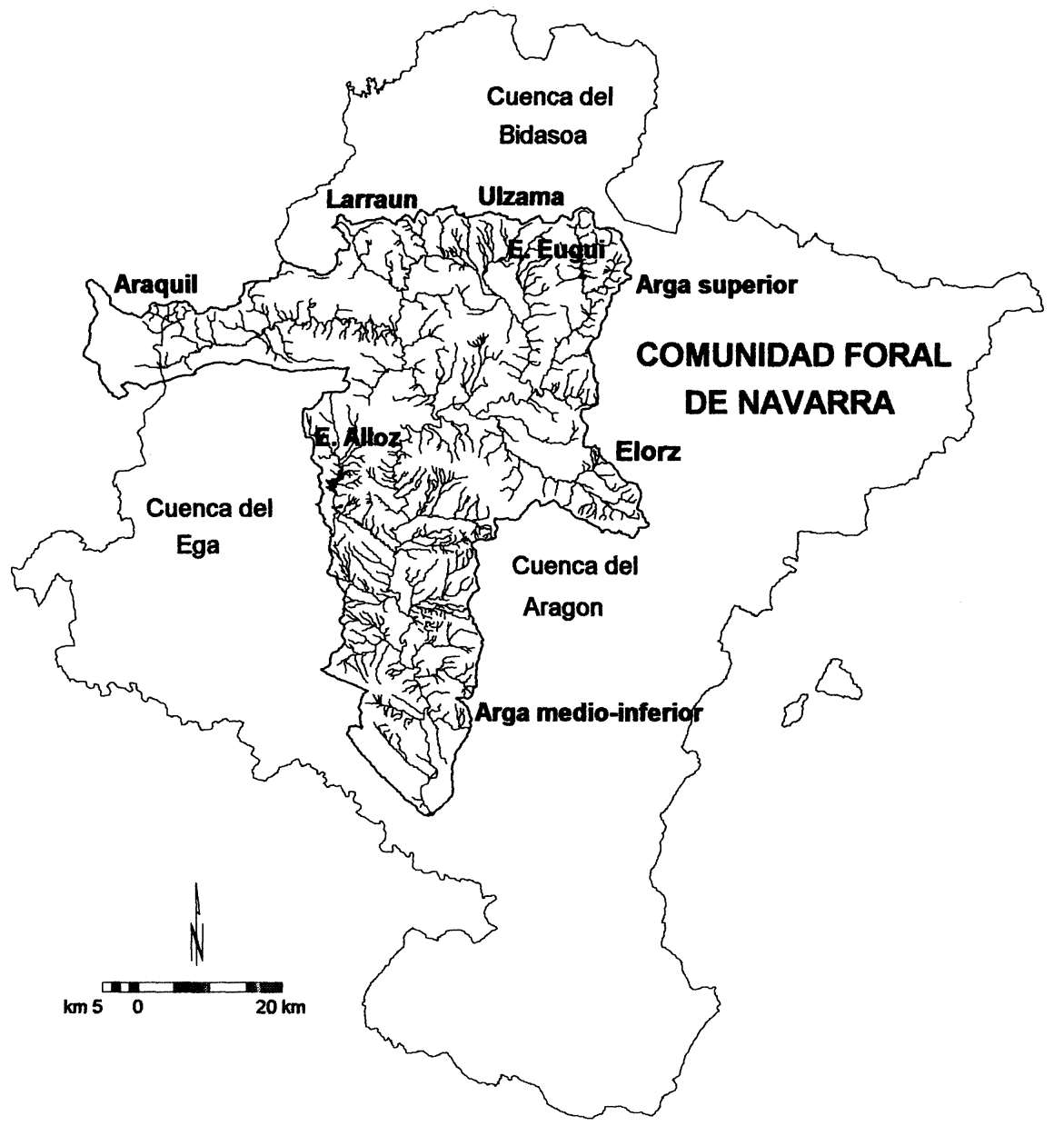

FIgURA 1.-Localización de la zona de estudio.

como «la originalidad geográfica de Navarra», muchos han sido los estudiosos que han definido este espacio como zona de fuertes contrastes.

En primer lugar, la diversidad topográfica de la cuenca del Arga obedece a la confluencia de elementos morfológicos tan dispares como los Pirineos Occidentales, las montañas y valles Vasco-Cántabros y la Depresión del Ebro. La altitud media es de 651 m, con una máxima de $1.493 \mathrm{~m}$ 
en el pico de Beriain (Sierra de San Donato) y una mínima de $276 \mathrm{~m}$ en la confluencia con el río Aragón.

Se pueden diferenciar dos espacios hipsométricos separados por las sierras de Urbesa-Andía, el Perdón y Alaiz. Al norte de estas alineaciones encontramos los relieves pirenaicos, de fuertes desniveles y

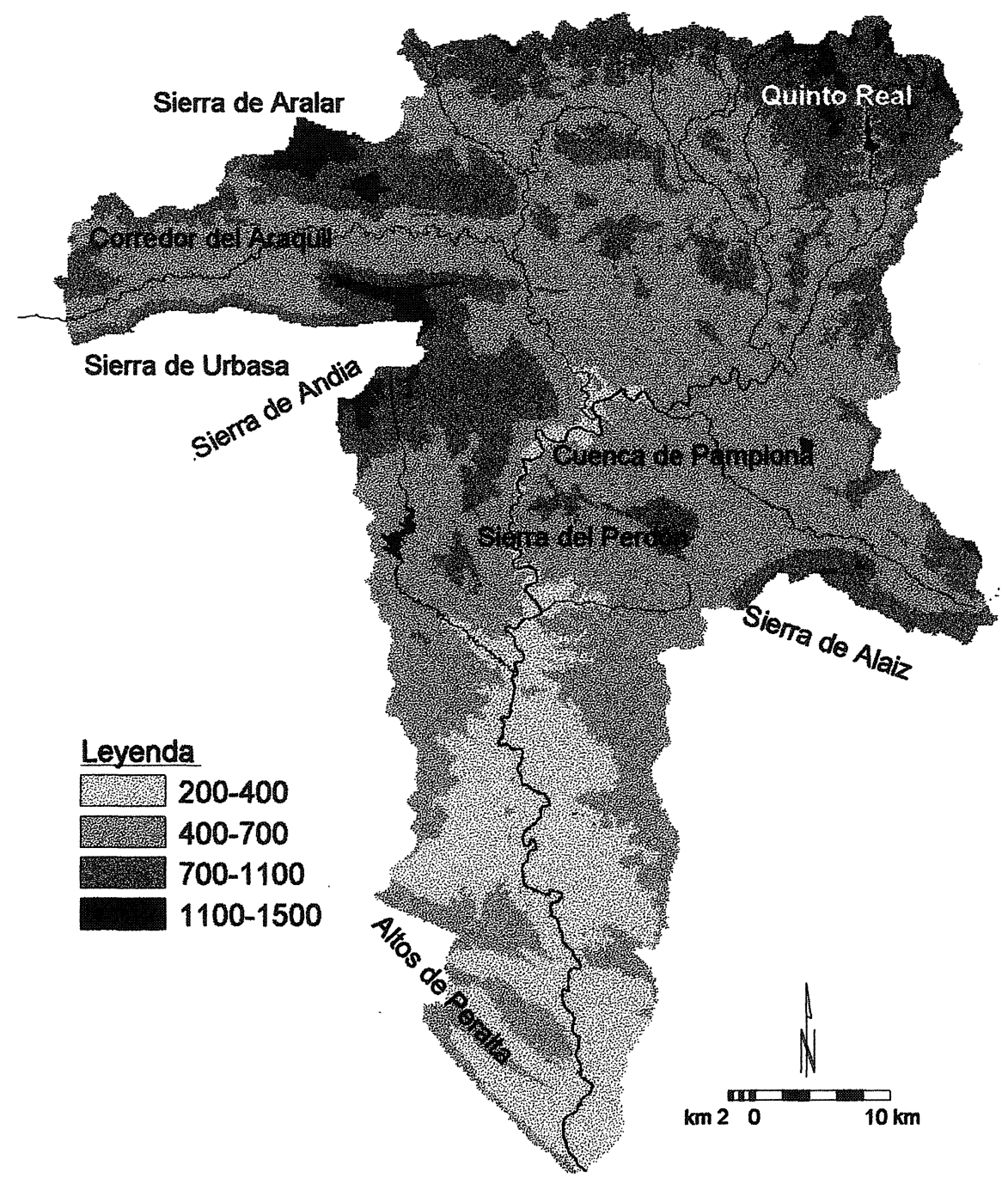

Figura 2a.-Mapa hipsométrico. 
acusadas pendientes, con altitudes superiores a $600 \mathrm{~m}$. Como excepciones, dos unidades deprimidas de origen tectónico-erosivo y topografía llana: el corredor del Araquil y la cuenca de Pamplona. Por el sur, el Arga penetra en la Depresión del Ebro, de topografía alomada, donde las altitudes raramente superan los $400 \mathrm{~m}$ (figura 2a).

La distribución frecuencial de pendientes mestra que más del $40 \%$ de la cuenca presenta desniveles considerables (> 20 \%) y en más del $25 \%$ del área las pendientes superan el $30 \%$. Estos valores aparecen concentrados en la zona pirenaica septentrional, mientras que desde la Sierra del Perdón hacia el sur, descienden considerablemente (el $26 \%$ del territorio está por debajo del $3 \%$ de pendiente, y el $45 \%$ por debajo de $10 \%)$.

En segundo lugar, los contrastes clímaticos obedecen al hecho de que la cuenca del Arga participa de las características atlántico-pirenaicas y mediterráneas, pasando por un complejo espacio de transición de abundantes matices locales (Floristán, 1951; Mensua, 1960; Bielza de Ory, 1972; Torres, 1971; Elías y Ruiz, 1982; Creus, 1983; Pejeanute, 1989).

Por lo general, los sectores septentrionales están afectados por perturbaciones que ocasionan precipitaciones abundantes y constantes a lo largo de todo el año. En este sentido es importante el descenso latitudinal de ramales de la corriente en chorro, que, durante los meses de otoño e invierno, propician la entrada de borrascas atlánticas (Pejenaute,

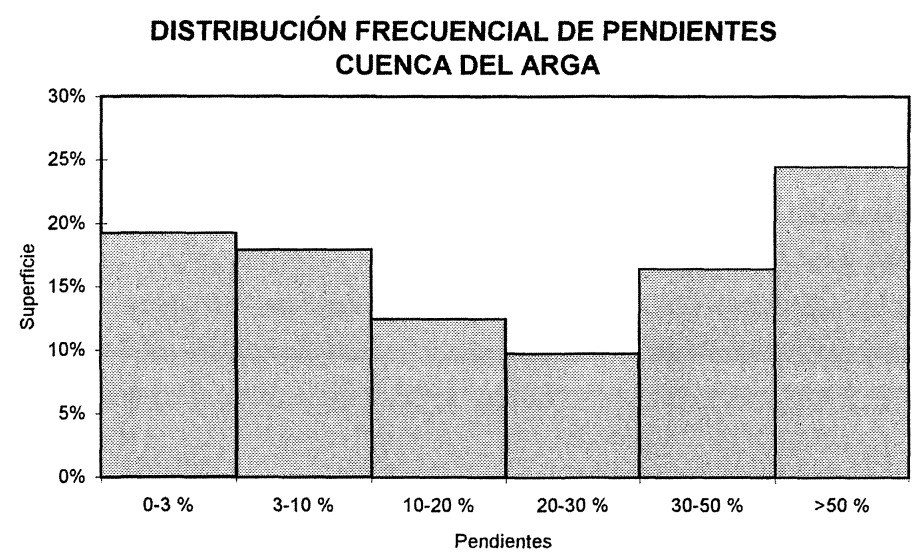

FIGURA 2b.-Distribución frecuencial de pendientes. 
1990). Las áreas meridionales, más protegidas contra este tipo de situaciones, se encuentran influenciadas por las altas presiones subtropicales. Las precipitaciones son más escasas, sobre todo en verano. Se aprecia, además, una clara tendencia a la continentalidad en sentido norte-sur que comienza a sentirse a partir de la Cuenca de Pamplona y se acentúa en la Navarra media y ribera, donde los contrastes térmicos alcanzan relativa notoriedad.

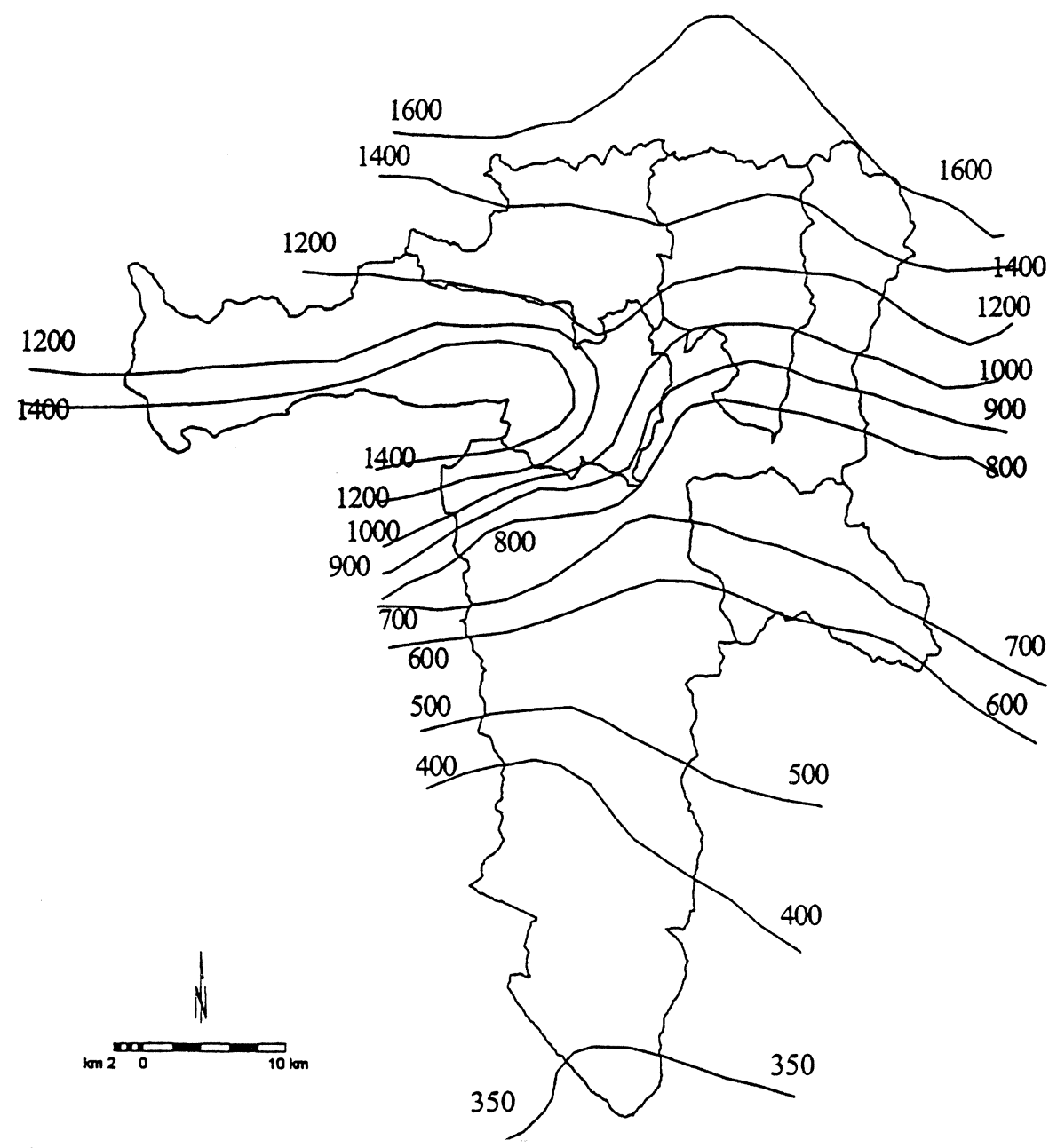

FIGURA 3.-Mapa de precipitación media anual en $\mathrm{mm}$. 
El efecto orográfico potencia los contrastes pluviométricos (figura 3). La disposición transversal de las principales alineaciones montañosas frente a los vientos húmedos atlánticos provoca, mediante el efecto föhn, un incremento de precipitaciones en los valles septentrionales, donde pueden superarse los $1.500 \mathrm{~mm}$ anuales, en detrimento de los meridionales, con totales de $400 \mathrm{~mm}$. Además, las borrascas de procedencia mediterránea tienen dificultades para penetrar en el sur de la Cuenca del Arga por la pantalla orográfica que supone la Cordillera Ibérica. También es debido al efecto orográfico la disminución de la humedad en sentido W-E (Creus, 1986). En consecuencia, en tan sólo 100 $\mathrm{km}$ de longitud existen acusadas diferencias climáticas entre el sector norte húmedo y de características térmicas suaves y el sector sur de escasas precipitaciones y régimen térmico continentalizado.

La situación meteorológica que origina con mayor frecuencia precipitaciones extremas corresponde a potentes borrascas que sitúan en las proximidades de Francia y atraen hacia Navarra masas de aire inestables de componente septentrional. Se trata de una circulación del Oeste en altura, de fuerte gradiente, que se ondula con anormal rapidez y adquiere una curvatura muy pronunciada. En 24 o 48 horas se puede pasar de una situación de Oeste, con aire suave y escasas lluvias, a otra de Noroeste o de Norte de gran inestabilidad. De este modo, lo que en principio es una vaguada fría acaba convirtiéndose en borrasca cerrada a niveles altos (Pejenaute y Beltrán, 1995). Las masas de aire cargadas de humedad se ven obligadas a ascender para sobrepasar las montañas del norte, descargando en forma de fuertes chubascos. En los sectores meridionales de la cuenca, las lluvias intensas son de tipo convectivo y se producen preferentemente en verano.

En tercer lugar, la cuenca del Arga participa de dos grandes dominios geomorfológicos: el pirenaico, labrado sobre materiales paleozoicos, mesozoicos y cenozoicos marinos fuertemente plegados, y la Depresión del Ebro, recubierta por materiales del Terciario Continental (Floristán, 1995, 1996; Castiella et al., 1952). La elevación del eje paleozoico de los Pirineos y el desplazamiento hacia el sur de cabalgamientos y mantos de corrimiento, que tuvo lugar durante la orogenia Alpina, configuraron estructuras de dirección W-E, que descienden paulatinamente de altitud hacia la Depresión del Ebro (Peña Monné, 1994). Procesos de intensa erosión diferencial durante finales del Plioceno y a lo largo del Cuaternario configuran un modelado que alterna relieves sobresalientes sobre 
la litologías duras (metamórficas y carbonatadas) y cuencas de excavación sobre los materiales blandos margoarcillosos. Los sedimentos arrancados al ámbito pirenaico se depositan en la Depresión del Ebro con potencias de más de $7.000 \mathrm{~m}$ (figura 4 ).

La diferente permeabilidad de las distintas formaciones geológicas condiciona el funcionamiento hidrológico del territorio. Los materiales

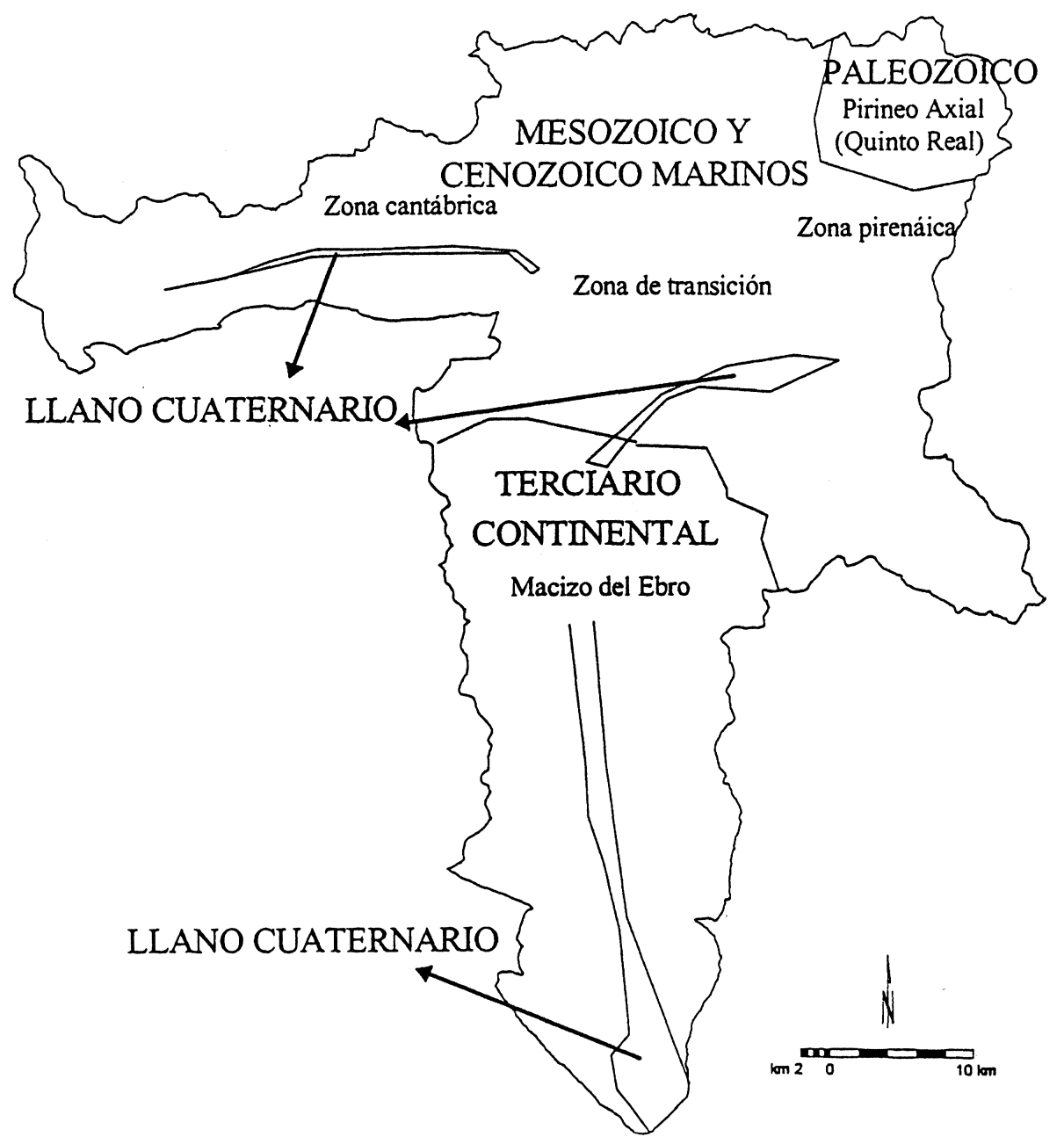

FIGURA 4.-Croquis morfoestructural 
primarios del macizo pirenáico de Quinto Real son, en general, impermeables; sin embargo, el nivel de fisuración de algunos de ellos permite la infiltración del agua de lluvia. En estas áreas, las condiciones climáticas y la densa cobertura vegetal, originan una zona superficial de alteración que desempeña un papel destacado en la retención de agua. Pequeñas corrientes de circulación subsuperficial se encargan de drenar el territorio hasta las laderas de las montañas o el fondo de los valles donde dan lugar a manantiales (Castiella et al., 1982).

En el área norte y centro de la cuenca, los materiales calizos han dado lugar a una morfología cárstica muy desarrollada e importantes acuíferos, sobre todo en las sierras de Aralar y Urbasa-Andia. Por el contrario, las amplias superficies de margas y arcillas del flysch potencian notablemente la escorrentía superficial. Debido a la existencia de niveles calizos intercalados en las margas, es frecuente encontrar pequeños cauces que repentinamente pierden su caudal al llegar a los materiales permeables. La Cuenca de Pamplona, formada por sedimentos de Terciario en facies marina, participa de estas características.

Los materiales del Terciario Continental propios de la Depresión del Ebro son, en general, impermeables. Los depósitos detríticos cuaternarios, abundantes en la cuenca baja, son los que permiten mayor infiltración del agua de lluvia y forman pequeños acuíferos que descargan, posteriormente, en manantiales dispersos o en los canales fluviales.

Por lo que respecta a la cobertura del suelo, en la cuenca del Arga pueden distinguirse dos áreas claramente diferenciadas. Por un lado, la zona norte y noroeste, con una cubierta vegetal extensa y densa de caducifolias atlánticas, que en episodios de precipitación moderada va a favorecer la intercepción e infiltración del agua de lluvia. Por otro lado, la Cuenca de Pamplona, la zona media y la ribera, con escasa cubierta vegetal natural y donde los cultivos de secano ocupan la mayor parte de la superficie (figura 5).

El sector septentrional pertenece al dominio biogeográfico eurosiberiano y presenta la mayor extensión arbolada de la cuenca, compuesta por hayedos (17\% de la superficie total, ocupando las montañas de la divisoria cantábrico-mediterránea desde Aralar hasta Quinto Real, la vertiente norte de Urbasa, la ladera este de Andía y las cumbres de Alaiz) y robles ( $6 \%$ de la cuenca, prolongándose por las partes más meridionales del sector). Los bosques atlánticos han dado paso, como consecuencia de la actuación antrópica, a matorrales tipo landa y a prados de diente.

$$
-398-
$$




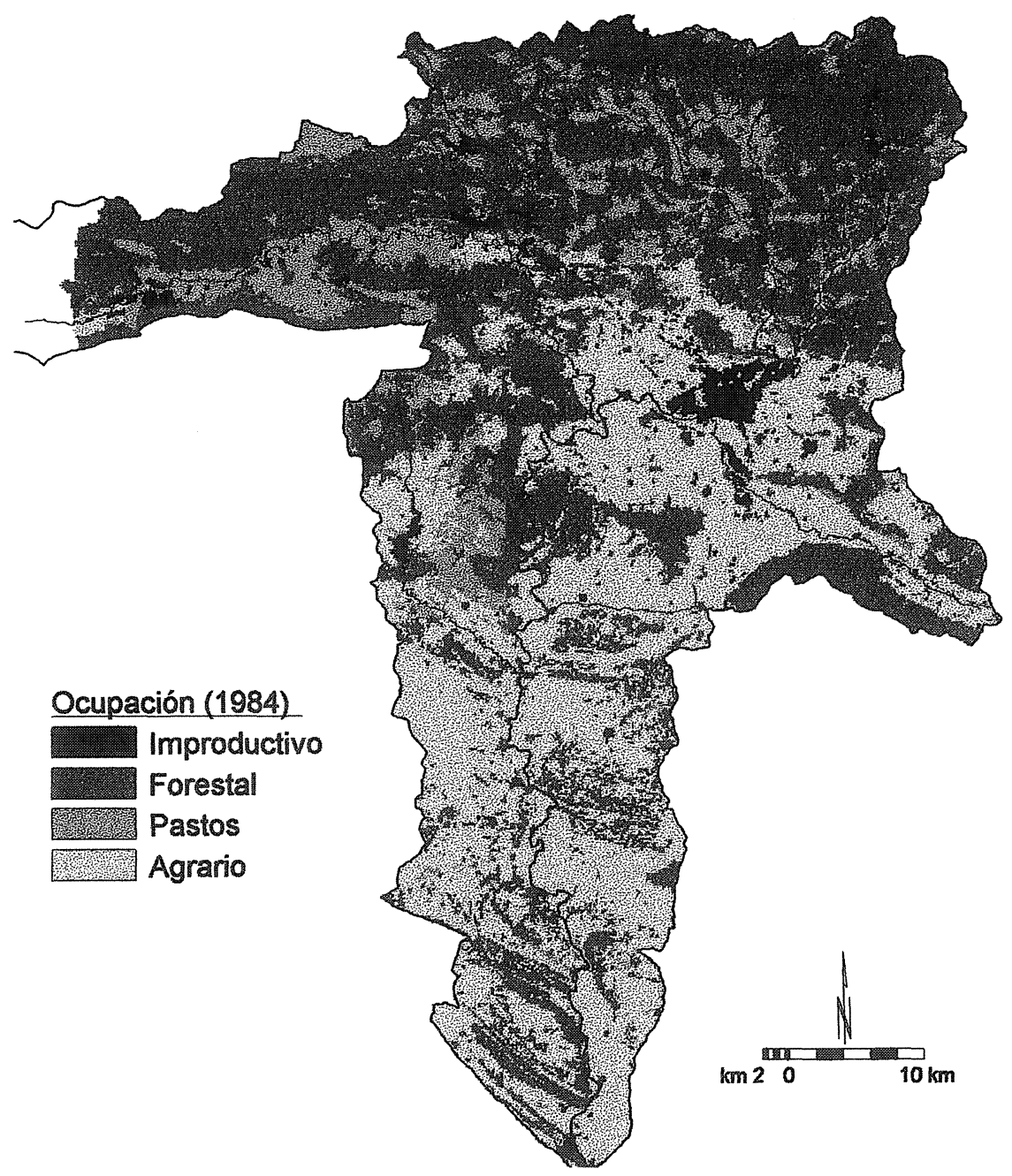

FIGURA 5.-Mapa de ocupación del suelo en 1984.

A medida que descendemos hacia el sur, los hayedos y robledales, y los prados de siega y diente pierden importancia en beneficio del cereal. El área mediterránea, como consecuencia de la intensa explotación a la que ha sido sometida, presenta un predominio del matorral mixto. Con una extensión de $147 \mathrm{~km}^{2}$ se localiza preferentemente en las partes

$$
-399-
$$


bajas de elevaciones topográficas y en áreas fuertemente deforestadas (como ejemplo la ribera del Arga).

La ocupación del suelo influye en la producción de escorrentía. En este sentido, en la cuenca del Arga las áreas con mayor capacidad de generar escorrentía superficial corresponden a las tierras con escasa vegetación de la cuenca media y la ribera, así como a núcleos de población de sustrato impermeable, como la ciudad de Pamplona. Le siguen las áreas cerealísticas de la Cuenca de Pamplona y la Depresión del Ebro y, después, los regadíos intensivos y huertas del bajo Arga. Por el contrario, los bosques densos de las áreas septentrionales y las frondosas de las partes bajas montanas favorecen la retención hídrica y su conducción hacia reservorios subsuperficiales y subterráneos.

La conjunción de las características climáticas y geomorfológicas determinan el régimen hidrológico del río. De nuevo aparecen los contrastes entre los rasgos pluvionivales de cabecera y mediterráneos de la cuenca baja. La suma de aportes de los afluentes principales (Ulzama, Araquil y Elorz) en la Cuenca de Pamplona hace que antes de Puente la Reina el río Arga sea ya un río caudaloso. En la desembocadura presenta un caudal medio de $57 \mathrm{~m}^{3} / \mathrm{s}$, consecuencia de su carácter alóctono en este tramo, donde el aporte no corresponde a las bajas precipitaciones de la zona, sino al suministro de cabecera (Jimeno, 1993).

La evolución de los caudales medios puede seguirse en el cuadro I. En cabecera (estación de Eugui), el río Arga presenta escaso caudal $\left(2,99 \mathrm{~m}^{3} / \mathrm{s}\right)$ y un régimen pluvionival, en el que las lluvias tienen mayor incidencia que las aguas de deshielo. En la cuanca media (estación de Echauri), el río ha recibido ya sus principales afluentes y tanto el caudal $\left(42,5 \mathrm{~m}^{3} / \mathrm{s}\right)$ como el coeficiente de irregularidad (5) han aumentado considerablemente. El máximo caudal corresponde a diciembre, pero los altos valores de marzo y abril permiten hablar a Floristán (1996) de un régimen pluvionival atenuado. Por último, en la cuenca baja (estación de Funes) el caudal alcanza $56,9 \mathrm{~m}^{3} / \mathrm{s}$, con máximos en febrero y caudales primaverales elevados. Aquí el río se ha vuelto mucho más regular, como consecuencia del carácter alóctono de este tramo: la dependencia de la lluvia se reduce y el río pasa a ser un mero transmisor y laminador del agua de cabecera (figura 6).

En síntesis, las características fisiográficas del río Arga condicionan una cuenca de hidrología compleja, de régimen pluvionival con dos sectores claramente contrastados. Un sector septentrional, desarro- 

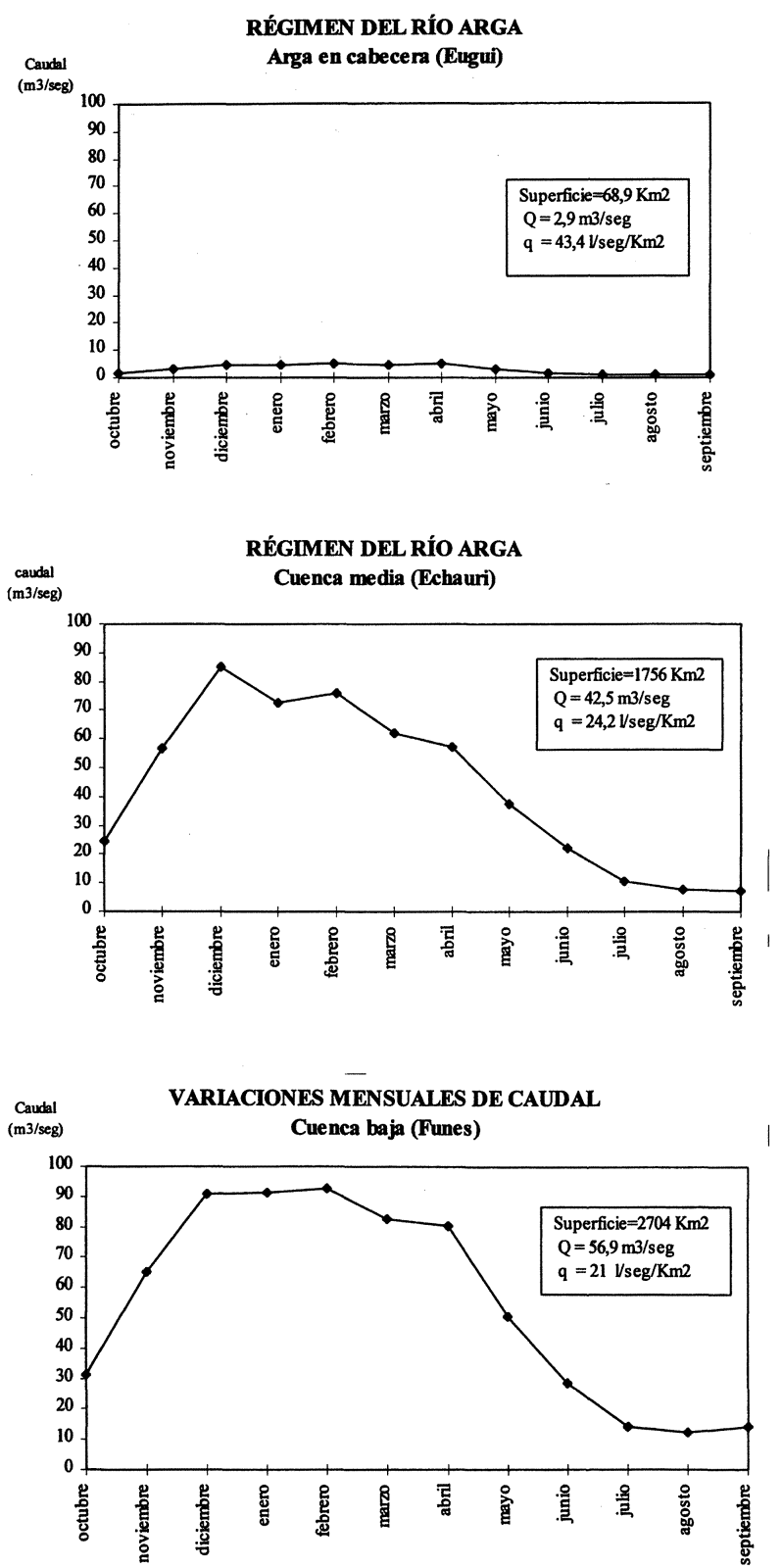

FiguRa 6.-Régimen del río Arga.

$$
-401-
$$


llado sobre materiales permeables (sierras calizas de Urbasa-Andia, Aralar y Alaiz), con densa cubierta vegetal, que propicia los procesos de infiltración del agua. Este sector es el que recibe, además, la mayor cantidad de precipitaciones, por lo que puede considerarse como importante fuente de recarga subterránea. A su vez, las grandes pendientes y el escaso desarrollo de los suelos implican elevados aportes de caudal al cauce. $\mathrm{Al}$ sector meridional corresponden las principales áreas productoras de escorrentía superficial, ubicadas sobre materiales impermeables (margas y arcillas terciarias) y cubiertas por cereal. Las precipitaciones aquí, son, sin embargo, considerablemente menores. En las partes bajas de este sector se abre, con dirección meridiana, el llano de inundación, avanzando progresivamente desde las últimas estribaciones de la sierra del Perdón hasta la confluencia con el río Aragón.

Dinámica de la ocupación humana.-A partir de los años 60, Navarra sufre un importante cambio estructural vinculado a procesos de desarrollo económico: fuerte industrialización y transformación agraria. Estos cambios conllevan la concentración de la población en el medio urbano, en detrimento de espacios más deprimidos, con tendencia al despoblamiento (Ferrer y Calvo, 1988; Ferrer et al., 1991).

La cuanca del Arga reúne, según el censo de 1991, un total de 328.436 habitantes, cuya distribución presenta un patrón desigual. En primer lugar destacan las zonas industriales, de crecimiento rápido y gran concentración poblacional: Area Metropolitana de Pamplona - AMP (80 \% de la población) - y Corredor del Araquil. En segundo lugar, aparecen las zonas de desarrollo agrícola, de crecimiento mucho más lento ubicadas fundamentalmente en las riberas del Arga. Por último, las zonas de montaña, de economía tradicional y poblamiento disperso, donde predomina el éxodo rural y el despoblamiento progresivo (figura 7).

Por los que respecta a las áreas industriales, cabe decir que el incremento de población más importante entre 1960 y 1991 se produce en el AMP. Se distinguen, no obstante, dos tendencias entre la capital (de expansión acelerada hasta 1975 en que se ralentiza, para alcanzar el crecimiento cero en 1981) y su área circundante, que mantiene una dinámica elevada durante todo el período. La clave de la expansión industrial reside en el auge del sector metalúrgico que, concentado durante los años 60 y principios de los 70 en la Cuenca de Pamplona, actúa como motor del cambio. Los sectores tradicionales (alimentación, papele- 


\section{EVOLUCIÓN DE LA POBLACIÓN}

ENTRE 1960 Y 1996

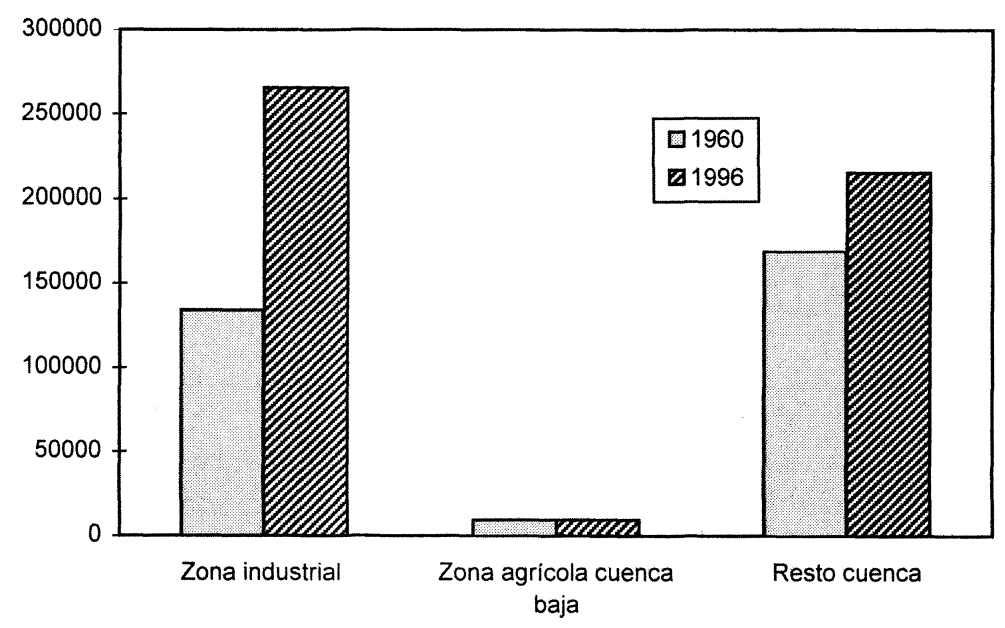

FIGURA 7.-Evolución de la población entre 1960 y 1990

ras, artes gráficas, textil, mueble) se modernizan y distribuyen en el espacio, siguiendo un modelo descentralizado de polígonos industriales. A partir de la crisis, la diversificación industrial del AMP se reduce preferentemente a los sectores de transformados metálicos y química (exceptuando Galar, donde predomina la minería).

El corredor del Araquil constituye el otro foco industrial radicado en la cuenca del Arga, de crecimiento más suave, favorecido por la proximidad de Guipúzcoa, el desarrollo del transporte y la riqueza del medio natural (canteras de escarpes calizos y bosques). Alsasua y Olazagutia son, en los primeros años, los principales núcleos de atracción de inmigrantes. La red férrea favorece el desarrollo de Alsasua como foco metalúrgico. Olazagutia se decanta por la explotación de los recursos naturales, fundamentalmente el cemento. A partir de 1975, se aprecia en el Corredor una fuerte especialización en construcción e industria básica (Huarte-Araquil e Irurzun).

En la ribera baja, tradicionalmente agraria, se observa, en los últimos años, la expansión de la industria de conservas vegetales, ligada al desarrollo técnico agrícola. El caso más significativo es el municipio de Peralta, que se incorpora al eje industrial del Ebro. 
La evolución del sector secundario hace que, en la actualidad, Navarra sea una de las zonas más industrializadas del país. Según el $C a$ tálogo de la Industria Navarra de 1995, en la cuenca del Arga aparecen registradas 745 empresas, con predominio de la pequeñs y mediana industria.

$\mathrm{El}$ sector agrícola también experimenta importantes cambios en las últimas décadas, ligados a grandes innovaciones técnicas y económicas. La transformación agrícola comienza con la concentración parcelaria, iniciada en 1954 (Rapún, 1986) con objeto de incrementar el rendimiento de las explotaciones (Malassis, 1958). Es importante, también, el intenso proceso de mecanización del campo navarro que implica la reducción drástica de la población activa agraria —el $49 \%$ en los años 60 frente al $11 \%$ en 1993 (Ugalde, 1990)—. Estas transformaciones son el reflejo de la crisis de la agricultura tradicional y la modernización del sector. Así, algunos cultivos tradicionales, como el trigo, el olivo, la remolacha o la avena, sufren una clara regresión, mientras que otros productos, como el espárrago, la cebada, el girasol o la colza, se extienden considerablemente. La mayor rentabilidad se obtiene en las riberas del Arga (sobre todo entre Larraga y la confluencia con el Aragón), donde han prosperado los cultivos herbáceos de regadío (cereales y hortalizas).

En síntesis, la dinámica de la ocupación humana en la cuenca del Arga durante los últimos treinta años se caracteriza por un notable desarrollo agrícola, industrial y urbano. Estas actividades, centralizadas preferentemente en los llanos aluviales (Cuenca de Pamplona, Corredor del Araquil y riberas del Arga) llevan implícitas un incremento considerable de las demandas hídricas y también ha aparecido, desgraciadamente, una mayor exposición al riesgo de inundación.

\section{El agua como recurso}

«El agua es un recurso natural raro, indispensable para la vida y las actividades económicas, irreemplazable, no ampliable por la mera voluntad del hombre, irregular en su forma de presentarse en el tiempo y en el espacio, vulnerable y susceptible de usos sucesivos» (Ley de Aguas). Esta constante se repite a lo largo de la Historia y atrae los núcleos de población a las riberas fluviales. El Arga no es una excepción. Más de cincuenta poblaciones, entre las que se encuentra Pam- 
plona, se han instalado en las vegas fluviales. De hecho, los testimonios del aprovechamiento hídrico del Arga datan desde época romana (Mezquiriz, 1991; Mezquiriz y Zubiaur, 1991).

$\mathrm{El}$ agua como recurso posee un carácter unitario, que se renueva con el ciclo hidrológico, y que conserva, a efectos prácticos, una magnitud casi constante en cada cuenca hidrográfica. Incluye, por tanto, las reservas superficiales y las subterráneas (Andreu y Estrella, 1993). Estas reservas tienen un determinado nivel de demanda, en función de los usos para las que sean requeridas. La dotación, o volumen de agua dedicado para cada uso, debe ser suficiente, con un margen de tolerancia que cubra déficits ocasionales. Cuando la dotación es inferior a la demada, existe una insuficiencia de recursos hídricos. El caso contrario implica la gestión inadecuada de los mismos (Nadal y Lacasa, 1993).

Las grandes transformaciones llevadas a cabo en la cuenca del Arga en los últimos años abren interrogantes acerca del grado de adecuación entre las reservas hídricas del río, las demandas a que está sometido, las dotaciones concedidas para cada uso y, en definitiva, la correcta gestión del recurso. Este apartado no constituye, ni mucho menos, un análisis exhaustivo de estas cuestiones. Únicamente pretende exponer algunos aspectos relevantes de las mismas.

Las reservas naturales.-El río Arga y sus afluentes de cabecera, bajo dominio climático atlántico-pirenaico, reciben gran cantidad de precipitaciones. Por ello, tanto a nivel superficial como subterráneo, constituye una cuenca de abundantes recursos.

En lo referente a los recursos superficiales, la cuenca del Arga presenta una aportacion media anual, en régimen natural, de $1.792 \mathrm{hm}^{3} /$ año. Las principales contribuciones provienen de los ríos Ulzama y Araqul, con $254 \mathrm{hm}^{3}$ (estación de Olave) y $990 \mathrm{hm}^{3}$ (estación de Asiain), respectivamente. Un seguimiento más detallado pone de manifiesto cómo, en cabecera (estación de Eugui), el río apenas aporta $94 \mathrm{hm}^{3}$. A medida que va creciendo la cuenca vertiente, los recursos aumentan también, y, en Huarte, se alcanzan los $195 \mathrm{hm}^{3}$. Es en Echauri, sin embargo, donde el incremento es más espectacular, porque el Arga ha recibido ya el caudal de sus tributarios principales, llegando a $1.340 \mathrm{hm}^{3}$. A cuatro kilómetros de su desembocadura en el Aragón (estacion de Funes), la aportación media anual sobrepasa los $1.792 \mathrm{hm}^{3}$ (figura 8). En la actualidad estos recursos están regulados por dos embalses: Eugui, localizado en 


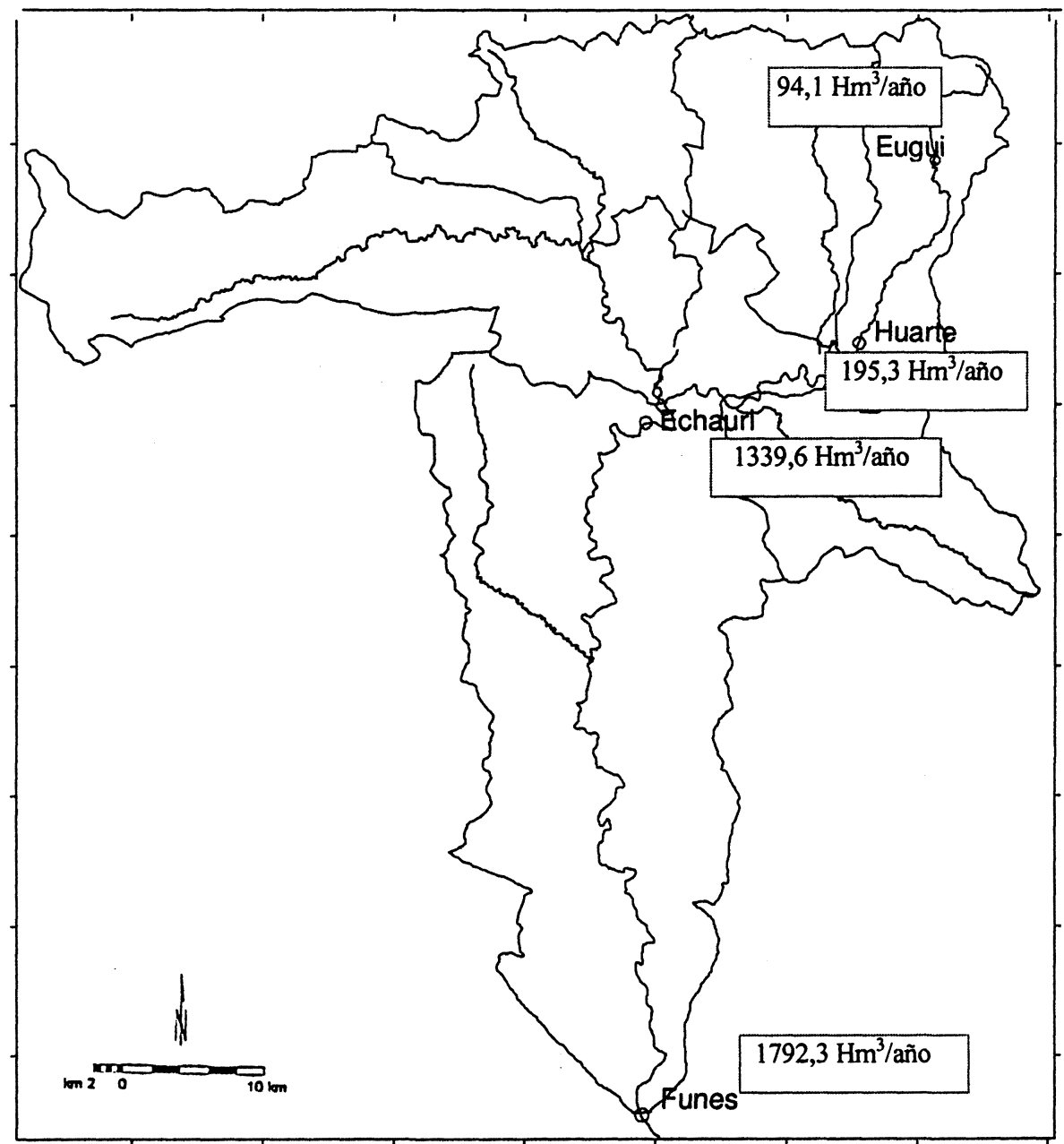

FiguRA 8.-Mapa de ubicación de las estaciones foronómicas.

la cabecera del río Arga, y Alloz, situado en la cabecera del río Salado (cuadro II).

Respecto a los recursos subterráneos, la cuenca del Arga participa de varias unidades hidrogeológicas diferenciadas, entre las que destacan: Andía, Aralar y el acuífero aluvial del Arga (Castiella et al., 1982). 

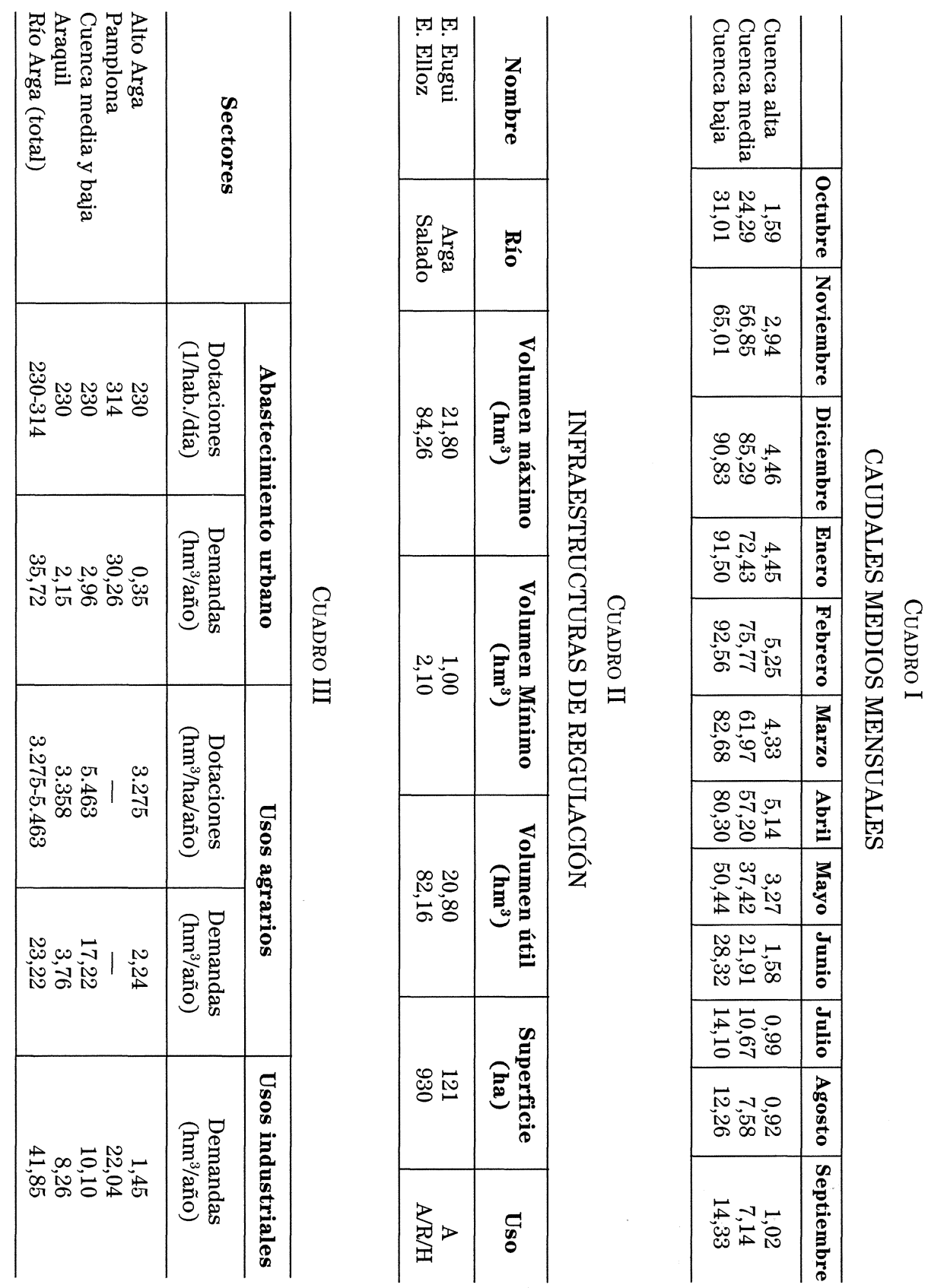

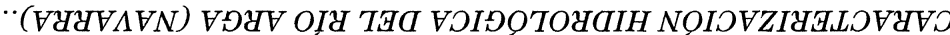


La subunidad hidrogeológica de Andía, debido a su compleja tectónica de fallas y pliegues ha condicionado la formación de tres importantes acuíferos con comportamiento hidrogeológico independiente y varios acuíferos aislados de menor entidad. Los más destacados son; Arteta, Riezu y Ibero-Echauri. Los dos primeros son de carácter libre y poseen, respectivamente, 100 y $80 \mathrm{~km}^{2}$ de área de recarga. El tercero, en parte libre y en parte confinado, posee $25 \mathrm{~km}^{2}$ de superficie de recarga. Los tres acuíferos son drenados, principalmente, por manantiales del mismo nombre. El caudal medio del Arteta es de $3,25 \mathrm{~m}^{3} / \mathrm{seg}$, y se utiliza para el abastecimiento de la ciudad de Pamplona, el de Riezu de $2,25 \mathrm{~m}^{3} / \mathrm{seg}$ y el correspondiente a Echauri e Ibero de $0,25 \mathrm{~m}^{3} / \mathrm{seg}$ en ambos casos. La capacidad total del acuífero de Arteta es de $80 \mathrm{hm}^{3}$ y se estima que la capacidad de embalse útil podría quedar reducida a unos $30 \mathrm{hm}^{3}$. En Riezu, la reserva es de $70 \mathrm{hm}^{3}$, estimándose que podría reducirse a unos $30 \mathrm{hm}^{3}$.

Los acuíferos más destacados de la unidad hidrogeológica de Aralar son: Iribas, Latasa e Irañeta. El primero posee $68 \mathrm{~km}^{2}$ de superficie de recarga, el segundo $18 \mathrm{~km}^{2}$ y el tercero $23 \mathrm{~km}^{2}$. Los principales manantiales son Aitzarreta, Iribas e Irañeta o Urruntzure. Aitzarreta drena la parte central de Aralar y su aportación íntegra recarga el acuífero de Iribas. El manantial de Iribas drena la parte norte de la sierra, mientras que Irañeta lo hace en la parte sur. Estos manantiales son muy irregulares; Iribas con un caudal medio de $2,64 \mathrm{~m}^{3} / \mathrm{seg}$, puede oscilar entre caudales de $35 \mathrm{~m}^{3} / \mathrm{seg}$ y $0,05 \mathrm{~m}^{3} / \mathrm{seg}$. A Irañeta y Latasa les corresponde caudales medios de 0,60 y $0,53^{3} / \mathrm{seg}$. El acuífero de iribas posee $50 \mathrm{hm}^{3}$ de reserva y unos recursos que ascienden a $84 \mathrm{hm}^{3} / a n ̃ o$. En Irañeta, la reserva es de $9 \mathrm{hm}^{3}$ y los recursos de $22 \mathrm{hm}^{3} /$ año y en Latasa, una reserva de $4,5 \mathrm{hm}^{3}$ proporciona unos recursos de $17 \mathrm{hm}^{3} /$ año.

El acuífero aluvial del Arga, con una superficie de $95 \mathrm{~km}^{2}$ y un espesor saturado medio de $10 \mathrm{~m}$, supone una reserva de $95 \mathrm{hm}^{3}$. La recarga procede de la infiltración de la lluvia directa, los excedentes de riego y las inundaciones por desbordamiento del río y almacenamiento en las riberas en momentos de fuertes crecidas, por lo que resulta difícil estimar el volumen correspondiente al recurso.

Principales demandas y dotaciones.-La correcta planificación y gestión hídrica conlleva, por un lado, la estimación de los recursos disponibles y, por otro, la evaluación de la demanda, esto es, la cantidad 
y calidad de agua necesaria para cada uso. Las diferentes actividades humanas que requieren agua se pueden dividir entre prioritarias y secundarias. Mientras las primeras precisan de agua dulce (abastecimientos urbanos, agrícolas, industriales y ecológicos), las secundarias, no (recreativos, navegación, energéticos). A su vez, los usos pueden ser consuntivos, si implican un consumo real del agua utilizada, o no consuntivos, si el agua puede ser reutilizada (Nadal y Lacasa, 1993).

El Plan Hidrológico de la Cuenca del Ebro establece como usos más importantes los consuntivos dedicados al abastecimiento urbano, agricultura e industria. En el marco de dicho Plan se ha aplicado un modelo matemático de simulación versión modificada del SIM-V) que ha permitido evaluar el balance entre las reservas hídricas y las demandas, en la actualidad y en el futuro inmediato (horizonte de los años 2005 y 2015). El cuadro III recoge la cuantía de las principales dotaciones y demandas actuales en la cuenca del Arga.

De todos los usos, el más importante es el de abastecimiento urbano, dedicado a cubrir las necesidades de los núcleos de población (consumo doméstico, servicios públicos, actividades industriales y comerciales ubicadas en el núcleo urbano y conectadas a la red general...). La dotación media por habitante y día varía en función del tamaño de la población, renta de los habitantes, clima, tipo de vivienda, hábitos sociales... En la cuenca del Arga, la dotación media es de 230 l/h/día, exceptuando la Cuenca de Pamplipona, donde sube a 314 1/h/día.

El extraordinario crecimiento urbano de esta comarca (en la actualidad concentra el $80 \%$ de la población) tiene un claro reflejo en las demandas hídricas. Desde fines del s. XviII hasta fines del XIX, Pamplona se abastecía de las aguas del manantial de Subiza (vertiente norte de la Sierra del Perdón). A partir de 1886 se obtiene la concesión de 70 l/s del manantial de Arteta. En 1943 se amplía el caudal detraído a 160 1/s y, en 1956, a 225 1/s. En 1962 este manantial se demuestra insuficiente para el abastecimiento urbano, por lo que el Ministerio de Obras Públicas emprende la construcción de la presa de Eugui. Conjugando los recursos del manantial con los del embalse se estimó cubrir las demandas hasta el año 2000. No obstante, dada la tendencia de la población a seguir concentrándose en esta área, el Plan Hidrológico contempla nuevas fuentes de abastecimiento, entre las que se encuentran la conexión del embalse de Arizarte con el de Eugui, o el incremento de captaciones subterráneas. 
Por lo que respecta al uso agrícola, destacar que el mayor consumo es requerido por el regadío. La dotación unitaria de riego suele variar entre 2.000 y $20.000 \mathrm{~m}^{3} / \mathrm{ha} / \mathrm{año}$ en función del clima, tipo de cultivo, prácticas de riego, suelo... En la cuenca del Arga las dotaciones medias varían entre 3.275 y $5.436 \mathrm{~m}^{3} / \mathrm{ha} /$ año. En total, los regadíos ocupan una superficie de $4.975 \mathrm{ha}$, lo que supone una demanda anual algo superior a los $23 \mathrm{hm}^{3}$. En los sectores de cabecera las necesidades de agua para riego son reducidas porque obedecen a pequeñas explotaciones, generalmente de trabajo a tiempo parcial, que carecen de regulación. Las principales demandas se generan en el Arga medio y bajo, donde se concentran las mayores extensiones de regadío ( $3.150 \mathrm{ha}$ ) y donde el aporte de lluvia meteórica es más reducido. Se requieren dotaciones de $5.436 \mathrm{~m}^{3} / \mathrm{ha} / \mathrm{año}$, que suponen un consumo anual de $17,22 \mathrm{hm}^{3}$.

En el horizonte del año 2005, el Plan Hidrológico contempla la extensión de la superficie regable en 1.700 ha, con una dotación de 6.637 $\mathrm{m}^{3} / \mathrm{ha} / \mathrm{año}$, lo cual implica un aumento de la demanda de $11,28 \mathrm{hm}^{3}$. Este incremento lleva aparejadas transformaciones en el regadío de muy diversa naturaleza, desde el riego de apoyo en el olivar y el almendro, con dotaciones muy reducidas, hasta los regadíos intensivos, con dotaciones en embalse elevadas.

Las demandas de agua para usos industriales son las más variables de todas y difíciles de evaluar, a pesar de que para los países desarrollados suponen entre el 70 y el $80 \%$ de los usos consuntivos. En la actualidad, el total de la demanda hídrica industrial en el Arga es de $41,85 \mathrm{hm}^{3} /$ año. Los mayores consumos se dan en la Cuenca de Pamplona $\left(22,04 \mathrm{hm}^{3} / \mathrm{año}\right)$. Le siguen en importancia el área media y baja $\left(10,10 \mathrm{hm}^{3} / a n ̃ o\right)$ y la subcuenca del Araquil $\left(8,26 \mathrm{hm}^{3} /\right.$ año $)$. No parecen existir razones para pensar en un aumento de las dotaciones industriales en el futuro. Antes al contrario, cabe esperar un decrecimiento por utilización más eficaz y reciclaje del agua. Las predicciones hechas en el Plan Hidrológico para el futuro inmediato contemplan, sin embargo, un incremento de más de $8 \mathrm{hm}^{3} /$ año en la demanda industrial por expansión del sector.

Aunque los usos consuntivos son los más importantes, la demanda de agua para usos no consuntivos adquiere relevancia, sobre todo, en el sector energético. En la cuenca del Arga existen, actualmente, once hidroeléctricas en funcionamiento: seis en el propio Arga (que requieren

$$
-410-
$$


un caudal de $152,4 \mathrm{~m}^{3} / \mathrm{s}$ ); dos en el Araquil (4,45 m³ $/ \mathrm{s}$ ); dos en Alloz $\left(24 \mathrm{~m}^{3} / \mathrm{s}\right)$, y una en Alzania $\left(1,1 \mathrm{~m}^{3} / \mathrm{s}\right)$. Dentro de los usos no consuntivos deben considerarse también tres piscifactorías (con una demanda total de $860 \mathrm{l} / \mathrm{s}$ ) y los caudales ecológicos o de compensación que deben asegurar los embalses de Eugui $\left(10,43 \mathrm{hm}^{3} / \mathrm{año}\right)$ y Alloz $\left(8,08 \mathrm{hm}^{3} / \mathrm{año}\right)$ para mantener los ecosistemas naturales.

En definitiva, se puede concluir que, actualmente, en la cuenca del Arga, no existen carencias hídricas. Las demandas se sirven con un $100 \%$, mientras que el $64 \%$ retorna nuevamente al sistema. Respecto a las tendencias para el futuro inmediato, se espera un crecimiento de la demanda, que será solventada mediante el aumento de explotación del recurso. En este sentido, el Plan Hidrológico contempla, entre otras, las siguientes actuaciones: puesta en explotacion de los embalses de Urdalur e Itoiz; aumento de las detracciones de los acuíferos de AralarUizama, Urbasa, Andía y los aluviales del eje del Ebro, regulación de la cabecera de Araia (Araquil), etc.

\section{El agua como riesgo}

La creciente ocupación de las vegas fluviales hace del Arga un río históricamente afectado por inundaciones. Diferentes obras -Estudio de inundaciones históricas en la Cuenca del Ebro (1985), Estudio y análisis de los riesgos de inundaciones en Navarra (1985), Proyecto Linde (1994) - recogen la relevancia de este riesgo natural, documentado desde 1527. Entre los casos más sobresalientes destacan: la inundación de octubre de 1787, que afectó a los pueblos entre Belascoain y la desembocadura; la de enero de 1850, de origen pluvionival; la de abril de 1915 que produjo grandes pérdidas en Pamplona y Peralta, donde se llegaron a medir $2.049 \mathrm{~m}^{3} / \mathrm{seg}$; la de febrero de 1952 , consecuencia de rápidos deshielos el río anegó terrenos desde Pamplona hasta Funes; la de 1980 en la que se registraron considerables destrozos a lo largo del valle principal, etc.

Por lo general, las cuatro estaciones foronómicas de la cuenca (Eugui, Huarte, Echauri y Funes) presentan crecidas de origen predominantemente pluvial, donde la mayor frecuencia de los caudales máximos se registran en invierno y, después, en otoño (figura 9). La influencia nival es poco significativa y se reduce a las áreas de cabecera, como el

$$
-411-
$$




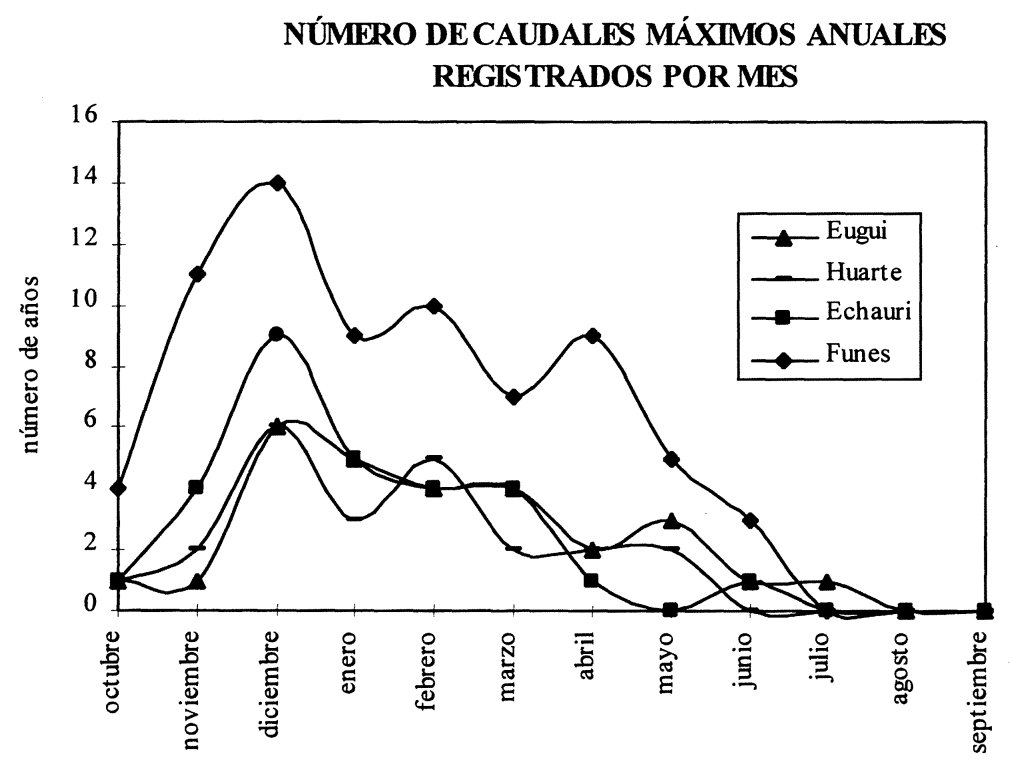

FIgURA 9.-Número de días de caudal máximo anual.

caso de Eugui, donde se registran avenidas primaverales relacionadas con el deshielo. Ya en Echauri se pierde gran parte de la influencia nival, y la aportación proviene mayoritariamente de la lluvia. En Funes, las características mediterráneas del clima provocan crecidas equinociales de origen exclusivamente pluvial.

Los caudales máximos de estas crecidas, junto con el período de retorno en que tienen una alta probabilidad de volver a producirse, aparecen en el cuadro IV. Para su cálculo se han utilizado las funciones de distribución de Gumbel y la Ley de Valores Extremos Generalizados (Nerc, 1975), porque son las más adecuadas para caudales máximos (Ferrer, 1993). Aunque las estimaciones teóricas abordan crecidas con períodos de recurrencia de hasta 500 años, es necesario remarcar que los valores más consistentes son los que corresponden a bajos períodos de retorno. Por encima de los 50 años los caudales deben entenderse únicamente como orientativos. Con objeto de proporcionar un orden de magnitud que ayude a interpretar estas cifras, sirva como referencia la crecida del 22 de enero de 1997, en la que se constató que caudales superiores a los $900 \mathrm{~m}^{3} / \mathrm{seg}$ (con un período de retorno de 25 años) supe-

$$
-412-
$$




\begin{tabular}{|c|c|}
\hline 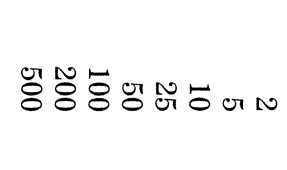 & 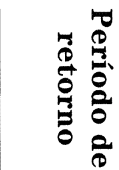 \\
\hline 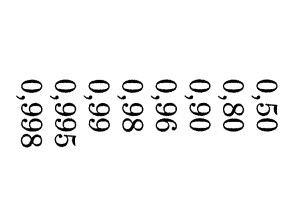 & 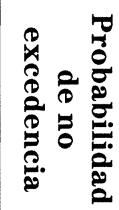 \\
\hline 总㤐句 $\& \infty 9$ & 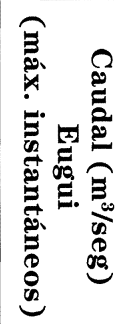 \\
\hline 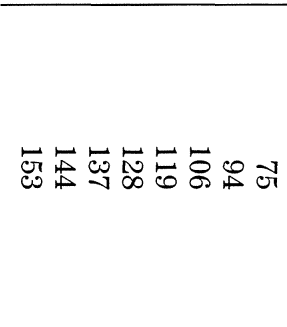 & 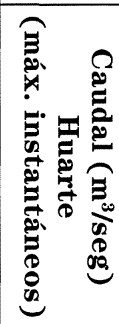 \\
\hline 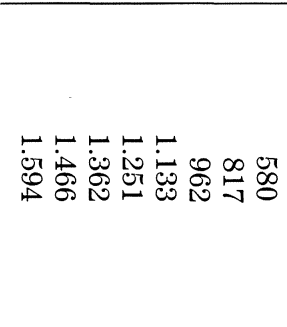 & 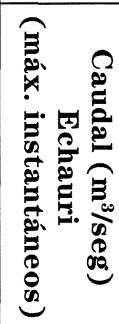 \\
\hline 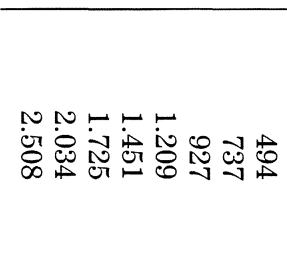 & 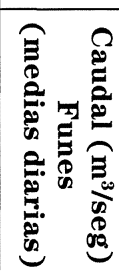 \\
\hline
\end{tabular}

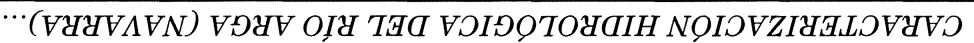


ran las motas de protección del Arga en el llano (Funes). Además, caudales inferiores a los de desbordamiento - alrededor de $700 \mathrm{~m}^{3} / \mathrm{seg}$ pueden provocar inundaciones locales, sin que se hayan superado los diques longitudinales de protección del cauce.

Con objeto de profundizar en las características de las crecidas que afectan a la cuenca del Arga, se han estudiado los sucesos más representativos de cada período de recurrencia. Parecen existir dos tipos distintos de hidrogramas. El más común, relacionado con precipitaciones prolongadas, abundantes y continuadas, presentan una evolución larga (tiempo de base entre seis y diez días), una morfología compleja (múltiples picos) y caudales punta moderados y sostenidos. El otro tipo, más esporádico, obedece a lluvias convectivas, de fuerte intensidad, y presenta hidrogramas simples (con un único pico), de rápido desarrollo (unos pocos días) y grandes caudales punta, de rápida evacuación.

La figura 10 muestra la evolución de la avenida de diciembre de 1980 (período de retorno de 10 años), como ejemplo del primer tipo. Esta crecida obedece a una situación de lluvias abundantes y generalizadas en toda la cuenca, que tuvieron lugar entre los días 14 y 22 , con un máximo secundario el día 15 y otro principal el día 19. El hidrograma refleja esta estructura y presenta dos picos (días 16/17 y 20), de los cuales el más importate es el segundo. El día 20 se registra el caudal punta en todas las estaciones. Los problemas de inundación empiezan a manifestarse a partir de la Cuenca de Pamplona, en que el Arga comienza a anegar las áreas adyacentes al canal. En Huarte, con un caudal de $82,4 \mathrm{~m}^{3} / \mathrm{seg}$, quedan cubiertos los tres arcos del puente del Calvario. En Pamplona se producen imporantes pérdidas: se inundaron las huertas de la Rochapea y Magdalena; se inutilizó la autopista Pamplona-Irurtzu; se anegó el campo de fútbol; se rebasó el puente de la Magdalena, etc. El máximo caudal punta ( $962 \mathrm{~m}^{3} / \mathrm{seg}$ ) se alcanza en Echauri, como consecuencia de los aportes del Araquil y el Ulzama. A partir de la Sierra del Perdón, las inundaciones se suceden afectando a Puente la Reina, Larraga y Miranda del Arga. Gran parte del territorio entre Peralta y Funes fue invadido por el Arga. El suceso fue especialmente crítico en Peralta, donde las aguas anegaron la parte baja del pueblo. El pico de avenida en Funes se reduce considerablemente como consecuencia del ensanchamiento del canal en el llano del Arga y la consecuente laminación de la crecida. 

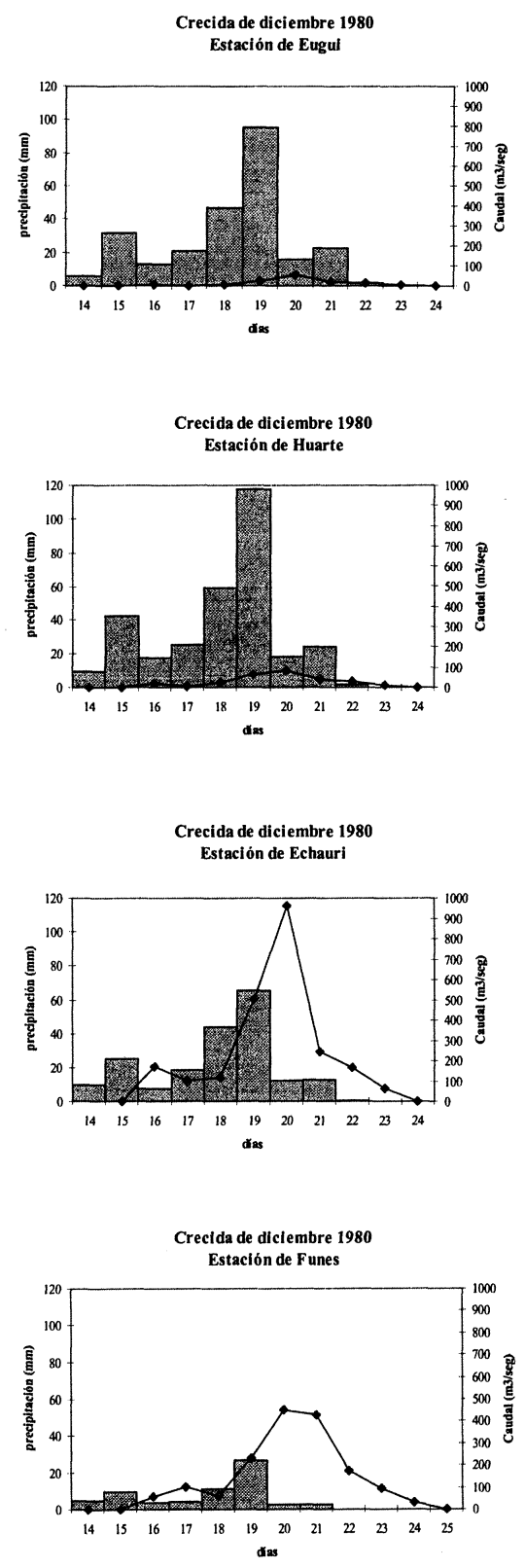

FiguRa 10.-Evolución de la crecida de diciembre de 1980.

$-415-$ 


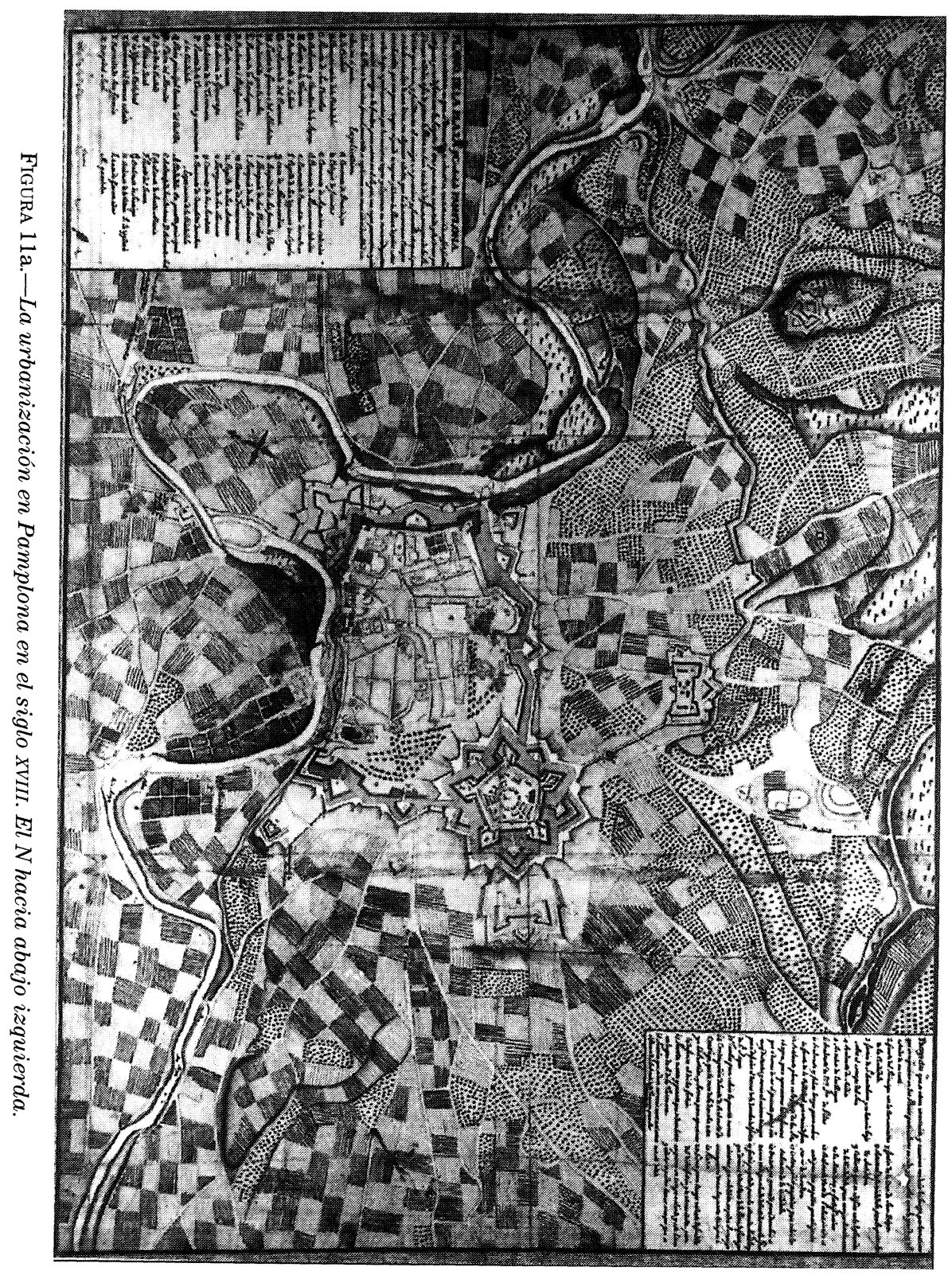

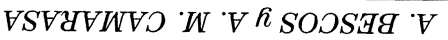


Como se ha podido constatar, el Arga presenta tramos con un alto riesgo de inundación. Dos zonas se demuestran especialmente conflictivas: la Cuenca de Pamplona y el llano aluvial del bajo Arga. En la Cuenca de Pamplona, varios condicionantes físicos propician los procesos de desbordamiento: abundantes precipitaciones, brusca reducción de la pendiente y confluencias críticas, bien de tributarios del mismo orden jerárquico (ríos Arga y Ulzama a pocos kilómetros de la ciudad), bien de afluentes de gran aporte (ríos Arga y Araquil). Tributarios del mismo orden, en contextos similares, suelen presentar parecidos tiempos de concentración y de traslación de la avenida, lo cual favorece la coalescencia de sus picos. A su vez, tributarios de gran aporte implican un incremento súbito del caudal punta. La escasa pendiente de la Cuenca de Pamplona y, como consecuencia, el curso meandrizante del canal en este tramo, reducen la velocidad de la corriente y favorecen los procesos de desbordamiento. La expansion urbanística e industrial de la ciudad en la llanura aluvial ha multiplicado el riesgo de inundación. La figura 11a pone de manifiesto cómo a finales del s. XviI la población se asentaba en las terrazas altas del río, libres de inundaciones, mientras en 1996 (figura 11b) ha crecido la ocupacion de territorios de alto riesgo, como son, entre otros, los barrios de la Magdalena, Rochapea y Chantrea, y el polígono industrial de Landaben.

El segundo espacio inundable corresponde a la parte baja de la cuenca, entre Berbizana y Funes. Atravesada la Sierra del Perdón, el río penetra en materiales fácilmente deleznables y amplía el valle considerablemente. Al mismo tiempo, se reduce mucho la pendiente y el canal comienza a meandrizar construyendo una amplia llanura de inundación, ocupada, fundamentalmente, por actividades agrícolas. La intensificación de estas actividades, por un lado, y la expansión de los núcleos de población en las riberas del cauce, por otro, ha supuesto, en las últimas décadas, un incremento considerable del riesgo de inundación.

Tanto las obras de protección construidas en la ciudad de Pamplona (escolleras, motas, muros de hormigón) como el encauzamiento de los últimos $10 \mathrm{~km}$, ya en el llano, se han demostrado insuficientes para crecidas de cierta entidad, como lo demuestra la inundación de enero de 1997. Por ello, son cada vez más necesarios estudios detallados que, desde el campo de la planificación, permitan un uso más racional del territorio. 


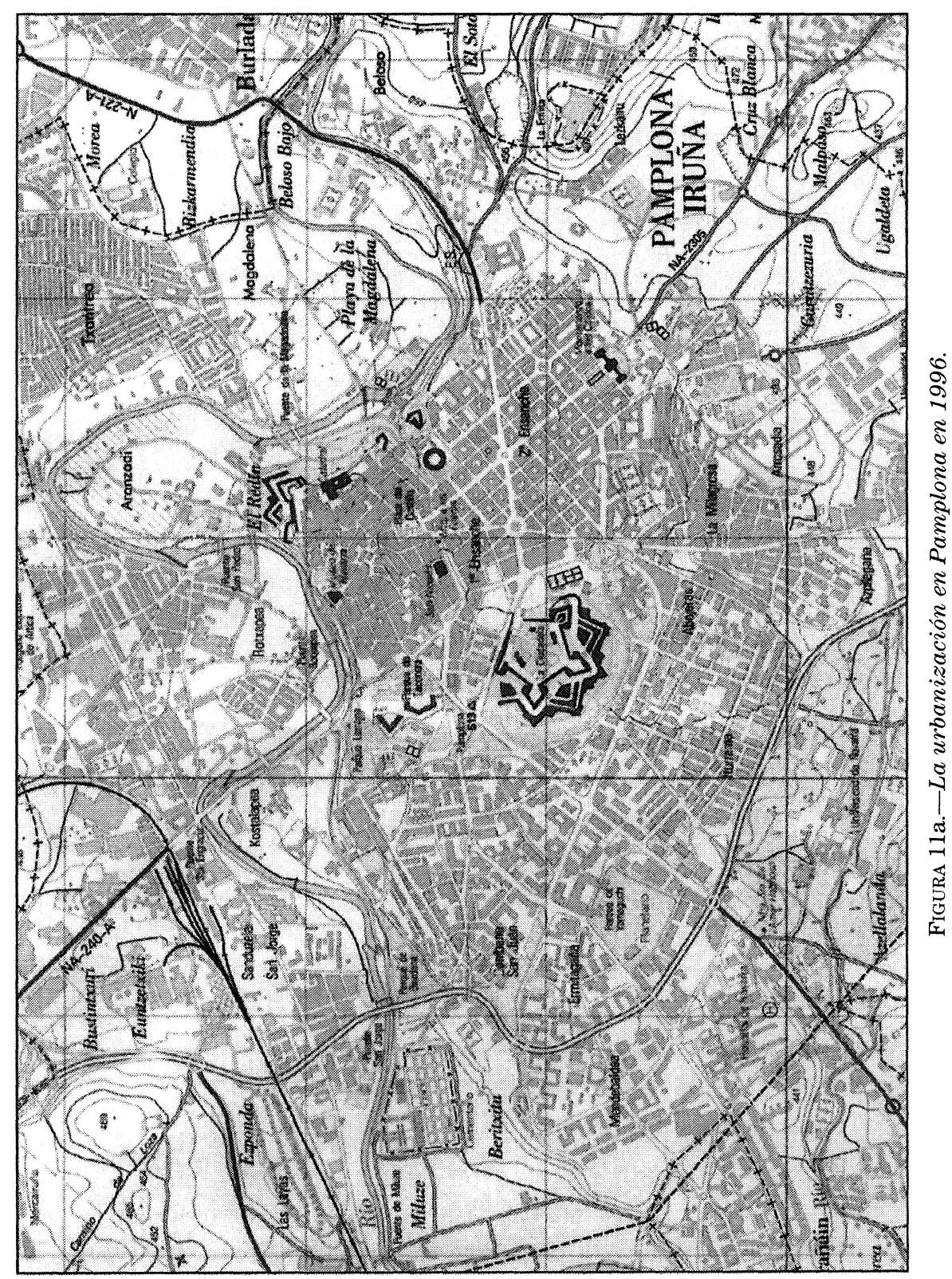

$-418-$ 


\section{Conclusiones}

El río Arga configura un espacio de características muy contrastadas, que están condicionando su funcionamiento hidrológico. Desde el punto de vista físico, se distingue el sector atlántico septentrional, que recibe una gran cantidad de precipitaciones. Funciona como área receptora y constituye una importante fuente de alimentación, tanto para las reservas superficiales, como para las subterráneas. El sector meridional, de rasgos mediterráneos, se comporta, sobre todo, como una zona de traslación y desbordamiento. Aquí los hidrogramas se laminan y el canal meandriza entre los depósitos del llano aluvial.

Sobre esta cuenca, la ocupación humana ha experimentado un crecimiento acelerado durante los últimos treinta años. El notable desarrollo urbanístico, industrial y agrario ha supuesto un incremento considerable de la demanda hídrica. Sin embargo, a pesar de que, en la actualidad, mantener las distintas actividades económicas requiere más de $100 \mathrm{hm}^{3}$ anuales, no existen carencias hídricas y ls demandas se sirven con un $100 \%$ de garantía.

Más preocupante resulta el factor riesgo. Dos zonas aparecen especialmente expuestas: la Cuenca de Pamplona y el llano aluvial del bajo Arga. Pese a las obras de protección contra avenidas (escolleras, muros, diques...) recientemente construidas en los sectores más conflictivos, el riesgo persiste. Caudales superiores a $900 \mathrm{~m}^{3} / \mathrm{s}$ (con un período de retorno de apenas 25 años) superan las motas de protección del canal en el llano. Picos menores $\left(700 \mathrm{~m}^{3} / \mathrm{s}\right)$ pueden producir inundaciones locales, aunque no se hayan rebasado las orillas.

En la Cuenca del Arga, la relación del hombre con el agua presenta un balance positivo en tanto recurso hídrico, a la vez que muy negativo en cuanto al riesgo de inundación. Existen reservar suficientes para mantener, incluso incrementar, las actividades económicas y urbanísticas actuales. Sin embargo, la ocupación indiscriminada de las vegas fluviales ha supuesto un considerable incremento de los niveles de riesgo. Llegados a este punto, se revelan imprescindibles las tareas de planificacion y ordenación territorial, que permitan aprovechar el recurso a la vez que evitar el riesgo. 


\section{BIBLIOGRAFÍA}

Beltrán, F.; Pejenaute, J. M. (1995): Las inundaciones en Navarra. Inédito. Dpto. de Estructuras Agrarias. Gobierno de Navarra. Pamplona.

Bielza DE ORY, V. (1972): Tierra Estella. Príncipe de Viana. Pamplona.

CASAS TORRES, J. M. (1956): La originalidad geográfica de Navarra. Cursos de verano en Pamplona, lección inaugural del I Curso. Universidad de Zaragoza. Diputación Foral de Navarra.

CASTiElla, J.; SolÉ, J.; Niñerola, S.; OtAMENDi, A. (1982): Las aguas subterráneas de Navarra. Proyecto hidrológico. Ed. Dirección de Obras Públicas. Servicio Geológico. Gobierno de Navarra. Pamplona.

—; FACI, E.; DEL VALLE, J. (1997): Memoria del Mapa Geológico de Navarra E. 1:200.000 (actualización). Servicio de Obras Públicas. Dpto. de Obras Públicas, Transportes y Comunicaciones. Gobierno de Navarra. Pamplona.

Creus, J. (1983): «Características agroclimáticas de Navarra». Boletín de Información Agraria el Campo, 91, pp. 10-14. Bilbao.

- (1986): «El clima de Navarra». En Lecciones de Geografía Navarra. Ed. Eunsa, Pamplona.

DEPARTAMENTO DE INDUSTRIA, COMERCIO Y TURISMO (1995): Catálogo de la Industria Navarra 1995. Departamento de Industria, Comercio y Turismo. Gobierno de Navarra. Pamplona.

ELÍAS, F.; RUIZ, L. (1982): Estudio Agroclimático de la provincia de Navarra. Instituto Navarro del Suelo. Pamplona.

Ferrer, M.; Calvo, J. J. (1988): «Población y sistema urbano». En Papeles de Economía Española. Economía de las comunidades autónomas, núm. 6, pp. 73-92. Caja de Ahorros de Navarra. Pamplona.

_ et al. (1991): «Microurbanización e industrialización local; el eje navarro-riojano del Ebro». En Ecología social y ambiente: Las ciudades medias y pequeñas Ed. Universidad de Navarra, S. A. Pamplona.

Floristán, A. (1951): La Ribera Tudelana de Navarra. Zaragoza. Príncipe de Viana, Juan Sebastián Elcano.

- (1995): Geografía de Navarra. «El Solar-1. Introducción general. Fundamentos geográficos naturales. Las montañas de la Montaña». Diario de Navarra. Pamplona.

- (1996): Geografía de Navarra. Diario de Navarra. Pamplona.

Gregory, K. J.; Walling, D. E. (1973): Drainage Basin Form and Process: A Geomorphological Approach. Arnold, London.

Jimeno, A. (1993): El río Arga (tramo Peralta-Funes): dinámica fluvial. Memoria de Licenciatura. Inédita. Dpto. de Geografía y Ordenación del Territorio. Universidad de Zaragoza. Zaragoza.

LÓPEZ BERMÚDEZ, F. et al. (1988): Geometría de Cuencas Fluviales: Las Redes de Drenaje del Alto Guadalentín. Proyecto LUCDEME. ICONA. Madrid.

MALASSIS, L. (1958): Economie des exploitations agricoles. Essai sur les structures et les résultats des exploitations agricole de grande et de petite superficie. Ed. Armand Colin. Paris.

Mensua, S. (1960): La Navarra Media Oriental. Instituto Juan Sebastián Elcano. Zaragoza. MEZquirIz, M. A. (1991): «El agua en la Historia. Época Antigua». En El agua en Navarra. Caja de Ahorros de Navarra. Pamplona.

- - Zubiaur, J. (1991): «El agua en la Historia. Época Medieval y Moderna». En El agua en Navarra. Caja de Ahorros de Navarra. Pamplona.

NADAL REIMAT, E. (1993): Introducción al análisis de la planificación hidrológica. MOPT. Madrid, 190 pp. 
Pejenaute GoÑI, J. M. (1989): «Los días de precipitacion elevada en Navarra y las situaciones atmosféricas que las originan». Notas y Estudios de Ciencias Sociales, 2, 1760. Centro Asociado de la UNED en Navarra. Pamplona.

_ (1990): «Las situaciones atmosféricas lluviosas en Navarra». Espacio, Tiempo y For$m a$, serie VI, Geografía, 113-150. Universidad a Distancia. Madrid.

- (1990): «Estudio de las precipitaciones torrenciales de agosto de 1983 en Navarra». Lurralde, 14, 117-142. INGEBA. San Sebastián.

Peña Monné, J. L.; Gutiérrez Elorza, M. (1994): «La Depresión del Ebro». En Geomorfología de España. Edición coordinada, Direc. Gutiérrez Elorza, M., Madrid.

RAPÚN, M. (1986): La agricultura de Navarra entre 1962 y 1982: Una aproximación general y comarcal a su proceso de transformación. Departamento de Agricultura, Ganadería y Montes. Gobierno de Navarra.

Roselló, V. M. (1989): «Los llanos de inundación». En Gil Olcina, A.; Morales Gil, A. (eds.): Avenidas fluviales e inundaciones en el Mediterráneo. Universidad de Alicante. C. A. M., pp. 243-285. Alicante.

SOlÉ SABARIS, L. (1951); Los Pirineos. El medio y el hombre. Ed. Martín, Barcelona.

TORRES, M. P. (1971): La Navarra húmeda del Noroeste. CSIC. Madrid.

UGALDE, A. (1990): La Cuenca de Pamplona: Transformaciones agrarias recientes en una comarca periurbana. 295 pp. Gobierno de Navarra. Dpto. de Educación, Cultura y Deporte. Pamplona.

RESUMEN: El agua constituye un elemento vital para el desarrollo de los ecosistemas naturales, así como de los enclaves humanos. La creciente ocupación antrópica de los valles aluviales está creando conflictos, cada vez más patentes, entre el uso del recurso y la prevención del riesgo.

Estos problemas adquieren una dimensión considerable en el caso del río Arga, afluente del Ebro. Se trata de una cuenca de régimen pluvio-nival que presenta importantes reservas de agua. La población y las actividades económicas que en ella se asientan vienen experimentando una importante expansión desde los años 60, vinculada, sobre todo, al desarrollo industrial (Cuenca de Pamplona) y agrícola (llano aluvial). En los últimos treinta años este crecimiento ha supuesto un aumento considerable de las demandas hídricas, a la vez que del riesgo de inundación.

El presente trabajo analiza los aspectos físicos que determinan el funcionamiento hidrológico de la cuenca del Arga, así como la presión antrópica sobre el llano aluvial. Se analiza la demanda hídrica y la ocupación de las zonas inundables, en un intento de caracterizar ambas facetas del agua: recurso y riesgo.

PALABRAS ClAVE: Recurso hídrico, riesgo de inundación, crecida, cuenca fluvial.

ABSTRACT: Water is an essential element for the development of both natural and human ecosystems. The increasing anthropic occupation of the alluvial valleys is causing increasing conflicts between the use of natural resources and the prevention of risks.

These problems can be found in the case of the river Arga, a tributary of the river Ebro (Spain). In this case we are dealing with basin with a rain and snow melt regime. Since the 60 's, the population and the economic activities in this area have experienced a very important expansion due to the industrial development in the Pamplona area and the agricultural improvements in the Arga flood-plain. In the last thirty years this increase has boosted hydrological demands and the flood risks.

This work analyses the physical aspects which determine the hydrological features of the Arga basin, as well as the anthropic pressure on the flood-plain. 
The hydrological demand and the occupation of the flood areas have been evaluated in an attempt to define both aspects of the water: resource and risk.

KEY WORDS: Hydrological resource, flood, risk, river basin.

RESUMÉE: L'eau constitue un élément fondamental pour le déroulement des écosystèmes naturels autant que des enclaves humains. La croisant occupation anthropique des vallées alluviales est en train de produire des conflits, de plus en plus évidents, entre l'usage du ressource et la prévention du risque. On a trouvé ces problèmes, au bassin versant du fleuve Arga, un affluent de la rivière Ebro. Il s'agit d'un bassin de régime pluvio-nival qui présente des importants ressources d'eau. La population et les activités économiques que y sont installées ont expérimenté une puissante expansion, lié surtout, au développement industriel (Pamplona) et agricole (plaine alluvial). Dans les dernières trente années, cet accroissement a supposé un considérable augmentation des demandes hydriques, au même temps que le risque d'inondation.

Le présente travail analyse les aspects physiques qui déterminent le fonctionement hydrologique du bassin versant du Arga autant que la pression humaine sur la plaine alluvial. On analyse la demande hydrique et l'occupation des zones inondables, en prétendant de caractériser la double facette de l'eau: ressource et risque.

Most CLÉs: Ressource hydrique, risque d'inondation, crue, bassin versant. 